\title{
LA TUTELA DEL DERECHO DE LA UNIÓN EUROPEA: LA CUESTIÓN PREJUDICIAL Y EL RECURSO POR INCUMPLIMIENTO
}

\author{
THE EUROPEAN UNION LAW CUSTODY: \\ THE PRELIMINARY RULING AND THE INFRINGEMENT \\ PROCEDURE
}

\author{
JORDI REGÍ RODRÍGUEZ*
}

Recibido: 16/08/2016

Aceptado: 11/10/2016

\begin{abstract}
Sumario: I.- INTRODUCCIÓN. II.- EL PROCEDIMIENTO DE INFRACCIÓN INICIADO POR LA COMISIÓN. 1. Presentación de denuncia ante la Comisión. Las garantías de la fase previa al Recurso por Incumplimiento. 2. Estudio de caso: La herramienta "EU Pilot" y el cumplimiento por España del Derecho de la Unión. III.- LA CUESTIÓN PREJUDICIAL. 1. Cuestión Prejudicial de Interpretación y Validez. 2. La omisión de la Cuestión Prejudicial. IV.- CUESTIONAMIENTO DE LA TUTELA DEL DERECHO DE LA UNIÓN EUROPEA, MEDIANTE LOS MECANISMOS DE LA CUESTIÓN PREJUDICIAL Y EL RECURSO POR INCUMPLIMIENTO. 1. La Discrecionalidad como elemento subyacente en los mecanismos del Recurso por Incumplimiento y la Cuestión Prejudicial V.CONCLUSIONES. VI. - REFERENCIAS.

Contents: I. - INTRODUCTION. II. - THE INFRINGEMENT PROCEDURE INITIATED BY THE COMMISSION. 1. Presentation of a complaint to the Commission. Guarantees of the prior phase to the Infringement Procedure. 2. Case Study: The "EU Pilot" tool and Spain's compliance of the EU Law. III. THE PRELIMINARY RULING. 1. Preliminary Ruling of Interpretation and Validity. 2. The omission of the Preliminary Ruling. IV. - QUESTIONING OF THE EUROPEAN UNION LAW CUSTODY THROUGH THE MECHANISMS OF THE PRELIMINARY RULING AND THE INFRINGEMENT PROCEDURE. 1. Discretion as an underlying element in the mechanisms of the Infringement Procedure and the Preliminary Ruling. V. - CONCLUSIONS. VI.- REFERENCES.
\end{abstract}

Resumen: Este artículo trata la comparativa de dos mecanismos que permiten al Tribunal de Justicia de la Unión Europea (en adelante, TJUE) controlar las acciones legislativas de los Estados miembros que pudieran ser contrarias al Derecho de la Unión mediante distintas herramientas administrativas y procesales de las que aquí trataremos en particular: la Cuestión Prejudicial como mecanismo para la tutela judicial efectiva y protección jurisdiccional y el Recurso por Incumplimiento como mecanismo que vela porque los Estados miembros cumplan con sus obligaciones previstas en el Derecho de la Unión Europea, procedimientos mediante los cuales el TJUE y la Comisión Europea tutelan y salvaguardan la efectividad del Derecho de la Unión Europea. Estos mecanismos, aunque pueden objetivamente tener el mismo fin y necesariamente

\footnotetext{
* Investigador de la Universidad Antonio de Nebrija. Profesor del Área de Derecho Público. Doctorado.

https://doi.org/10.17561/rej.n16.a6
} 
disponer de un desenvolvimiento similar, observaremos como son esencialmente diferentes en su concepción y presentan particularidades que nos invitan a reflexionar.

Palabras clave: TJUE, La Comisión Europea, Cuestión Prejudicial, Recurso por Incumplimiento, EU Pilot.

Summary: This article is about the comparison of two mechanisms that allow the Court of Justice of the European Union to control the legislative actions of the Member States. These actions may be contrary to the EU law through various administrative and procedural tools, in particular the Preliminary Ruling as a mechanism for effective judiciary protection, and the Infringement Procedure as a mechanism that ensures that Member States comply with their obligations under the EU law procedures, by which the CJEU and the European Commission safeguard the effectiveness of the EU law. These mechanisms, although they can objectively have the same purpose and necessarily have a similar development, are essentially different in their conception and they have particularities that invite us to reflect.

Keywords: CJEU, The European Commission, The Preliminary Ruling, The Infringement Procedure, EU Pilot.

\section{I.- INTRODUCCIÓN.}

La aplicación del Derecho de la Unión, dentro de la conocida como "Comunidad de Derecho" establecida entre sus socios, se presume constituida en un sustrato fáctico material que pone de manifiesto la idoneidad de la aplicación de los intereses comunitarios consagrados en los Tratados. En este sentido, el TJUE tiene como principal función controlar la legalidad ${ }^{1}$ de los actos de la Unión y garantizar el respeto al Derecho en la interpretación y aplicación uniforme de la legislación europea en su transposición a las normativas de los Estados miembros, siendo el órgano jurisdiccional europeo competente para conocer, en su defecto, la posibilidad de articular en el marco de distintos procedimientos de remisión prejudicial, en una prolija serie de procedimientos $\mathrm{y}$ recursos administrativos y procesales para salvaguardar su cumplimiento $^{2}$. Entre los distintos recursos que conoce el TJUE, observaremos con

\footnotetext{
${ }^{1}$ Véase para un mayor abundamiento en el control de la legalidad por parte de la UE; FARAMIÑÁN GILBERT, J, M. de, "El Contencioso de la Unión Europea. El control de la legalidad en la Unión Europea”, en Tratado de Derecho y Políticas de la Unión Europea, Tomo V Sistema jurisdiccional de la UE (dirigida por Dr. J, Ma BENEYTO PÉREZ) Editorial Aranzadi, Thomson Reuters, 2012, p. 324, donde el citado autor describe las tres modalidades básicas para el control directo comunitario sobre la validez de los actos legislativos de la Unión, siendo tales: el Recurso de anulación previsto en el artículo 263 del TFUE, que se establece como un recurso directo y natural, sometida su admisibilidad a un plazo de dos meses; el Recurso por omisión previsto en el artículo 266 del TFUE, que formaliza la otra cara del contencioso, ante una abstención que haya sido declarada contraria a los Tratados y la excepción de ilegalidad prevista en el artículo 277 del TFUE, que se establece como un procedimiento de control incidental de los actos comunitarios de alcance general y que puede ser planteado en el desarrollo de un litigio principal sometido al TJUE, a pesar de transcurridos el plazo previsto en el artículo 263 del TFUE.

2 El control de la legalidad en la Unión Europea, implica buscar el equilibrio entre la acción del poder judicial en manos del Tribunal de Justicia frente al poder ejecutivo-administrativo de las instituciones, órganos y organismos que conforman el entramado de la Unión. Citado en FARAMIÑÁN GILBERT, J,
} 
detenimiento dos mecanismos que nos han llamado la atención por sus cualidades y que iremos describiendo hasta finalizar con nuestra consideración al respecto.

La Cuestión Prejudicial, en su faceta interpretativa del Derecho de la Unión, ha adoptado un rol que la diferencia de otros mecanismos procesales debido a que le permite ir más allá de determinar o interpretar dudas respecto de la materialización por los Estados miembros del Derecho de la Unión, desencadenándose la Cuestión Prejudicial como mecanismo procesal para la tutela judicial efectiva e interpretativa del Derecho de la Unión sobre cualquier tema que sustancien sus ciudadanos y empresas, ante la necesidad de amparo y tutela, produciendo efectos en el ordenamiento del Estado en el que la cuestión fuera planteada y extendiendo a todos los Estados miembros las cuestiones análogas ${ }^{3}$ analizadas por el Tribunal. El otro mecanismo que analizaremos, el Recurso por Incumplimiento ${ }^{4}$, no contempla esta dimensión de protección de la tutela judicial efectiva, que por el contrario sí se sustancia en la Cuestión Prejudicial.

En el caso del Recurso por Incumplimiento, este comprende tanto las acciones no conformes con las normas comunitarias, la constatación de la infectividad de las transposiciones defectuosas existentes y la ayuda a la depuración y mejora del ordenamiento interno, así como las omisiones cuando hay una obligación de hacer. Igualmente, la Comisión Europea cumple una importante misión, como garante de su cumplimiento, al seleccionar aquellas áreas o prácticas de los Estados miembros que van a ser perseguidas en los casos que se detecten infracciones del Derecho de la Unión disponiendo la Comisión de una atribución discrecional que le otorga un poder de apreciación para presentar o no la demanda de incumplimiento, aportando al TJUE los elementos necesarios para la prueba del incumplimiento que no podrán fundamentarse en presunciones (Public Policy Instrument), asegurándose la Comisión Europea la garantía y efectividad del Derecho de la Unión Europea "la última ratio que permite hacer prevalecer los intereses comunitarios consagrados por los Tratados contra la

M. de, “El Contencioso de la Unión Europea. El control de la legalidad en la Unión Europea”. Ob. Cit p. 325.

3 Sentencia del TJUE de 13 de noviembre de 2003, asunto C-42/02 (caso Lindman), (su argumento vale también para la sentencia del TJUE de 6 de octubre de 2009, Comisión de las Comunidades Europeas contra Reino de España, Asunto C-153/08). El Tribunal declaró que la normativa finlandesa que sometía a tributación el premio otorgado a un residente por un sorteo de lotería celebrado en otro Estado miembro era contraria al Derecho de la Unión Europea. En España, la exención contemplada en la letra ñ del artículo 7 de la Ley del IRPF exclusivamente para los premios nacionales debería interpretarse de manera extensiva para los premios de loterías organizados en otros Estados miembros. En este sentido, España no modificó su normativa y la Comisión inició un Recurso por Incumplimiento, que culminó en la condena a España por parte del Tribunal al no declarar exentos los premios otorgados por loterías establecidas en otros Estados miembros, poniéndose de manifiesto el posible efecto combinado que pudiera darse entre la Cuestión Prejudicial y el Recurso por Incumplimiento a los efectos de garantizar el cumplimiento del Derecho de la Unión Europea.

${ }^{4}$ La legitimación activa del Recurso por Incumplimiento, corresponde a la Comisión y a cualquier Estado miembro, articulándose el procedimiento en dos fases: una primera fase administrativa o pre contenciosa, en donde la Comisión Europea, estima que hay incumplimiento del Derecho de la Unión, y comunica al Estado las medidas necesarias para ponerle fin, emitiendo un dictamen motivado, en el que se exponen los fundamentos de hecho y derecho, ante el Estado infractor, fijando un plazo razonable para el cumplimiento de la obligación y una segunda fase, contenciosa propiamente dicha ante el TJUE, que se inicia agotado el plazo discrecional ofrecido por la Comisión, sustentándose en los mismos motivos que la carta de emplazamiento inicial con la que la Comisión inició el procedimiento. 
inercia y la resistencia de los Estados miembros” y la primacía de los Tratados acordados entre los socios de la Unión, velando porque estos no infrinjan la efectividad del Derecho de la Unión, elaborando normas contrarias a este (Security and the Rule of Law) y obteniéndose del TJUE una sentencia vinculante para el Estado miembro afectado donde se hubiere constatado el incumplimiento.

Hay que indicar que existe un procedimiento posterior $^{5}$ a la sentencia por incumplimiento el cual está dirigido a forzar su ejecución mediante la imposición de una multa coercitiva y que trataremos con posterioridad.

Es necesario señalar, para vehicular el contenido de este artículo, que tanto la Cuestión Prejudicial como el Recurso por Incumplimiento, como veremos en adelante, no se comportan como compartimentos estancos, sino que en multitud de casos ambos procedimientos se solapan sobre una misma materia.

\section{II.- EL PROCEDIMIENTO DE INFRACCIÓN INICIADO POR LA COMISIÓN}

La "Comunidad de Derecho" instaurada en la Unión, además de atribuir derechos a sus socios, también impone una serie de obligaciones a estos de modo que cumplan con las que les corresponden en virtud del bloque normativo integrado por los Tratados constitutivos con la finalidad que, tanto las instituciones comunitarias como los Estados miembros y los propios Ciudadanos de la Unión, se sometan a su Derecho. En consecuencia, los actos de Derecho derivado con fuerza vinculante (reglamentos, directivas y decisiones), los acuerdos externos e internacionales firmados por la Unión Europea en el ejercicio de sus fines, así como los principios generales del Derecho y sentencias del Tribunal de Justicia de la Unión Europea, tal y como la doctrina y la jurisprudencia del propio Tribunal describen, se integran en los ordenamientos jurídicos de los Estados miembros, obligándose estos a aplicarlo de acuerdo a los principios de primacía y efecto directo ${ }^{6}$, esto es: el Derecho europeo forma parte integrante del

\footnotetext{
${ }^{5}$ Desde el Tratado de Maastricht existe un procedimiento posterior a la sentencia dirigido a forzar su ejecución. Si la Comisión estima que el Estado condenado no ha tomado las medidas apropiadas, puede iniciarse un nuevo proceso que conduce a la imposición por parte del TJUE del pago de una suma a tanto alzado o de una multa coercitiva. Ver para mayor abundamiento: ANDRÉS SÁENZ DE SANTAMARÍA, M.P., GONZÁLEZ VEGA, J. y FERNÁNDEZ PÉREZ, B., Introducción al Derecho de la Unión Europea, $1^{\text {a }}$ edición, Eurolex, Madrid, 1996, p. 360.

${ }^{6}$ El principio del efecto directo del Derecho comunitario en los Estados miembros, permite a los Ciudadanos Europeos invocar directamente las normas del Derecho de la Unión ante sus tribunales nacionales. Ejemplos paradigmáticos de esta jurisprudencia del tribunal de justicia son distintos dictámenes que comienzan por la sentencia Van Gend \& Loos en 1963 donde el recurso presentado planteaba la cuestión del conflicto entre una normativa nacional y las normas del Tratado CEE, y donde el Tribunal de Justicia se pronunció sobre la misma, a raíz de la petición de decisión prejudicial de un tribunal neerlandés, proclamando la doctrina del efecto directo, que en este caso otorgaba a Van Gend \& Loos una garantía directa ante el órgano jurisdiccional nacional de sus derechos derivados de la normativa comunitaria. En 1964, la sentencia Costa estableció la primacía del Derecho comunitario sobre una normativa de carácter interno y si esta era compatible con determinadas normas del Tratado CEE, formulando el Tribunal de Justicia en este asunto, la doctrina de la primacía del Derecho comunitario basado en la naturaleza específica del ordenamiento jurídico comunitario que obliga a aplicarlo de manera uniforme en todos los Estados miembros. Ya en 1991, para nuestro interés en este artículo, en la sentencia Francovich y otros, el Tribunal de Justicia desarrolló el concepto fundamental de la responsabilidad de un
} 
ordenamiento jurídico de los Estados miembros que son responsables de transponerlo y aplicarlo correctamente. Como consecuencia de ello, todo Ciudadano de un Estado miembro tiene derecho a exigir a las autoridades del país que se observe correctamente tanto su derecho propio como el derecho que le asiste como Ciudadano Europeo, pudiendo denunciar ante la Comisión una medida (legal, reglamentaria o administrativa) o una práctica de un Estado miembro que considere contraria a una disposición o principio de Derecho de la Unión.

Esta aplicación del Derecho de la Unión, según MARTÍN DELGADO, se entiende por aplicar o implementar el Derecho como "[...] contribuyendo a que una norma europea tenga aplicación práctica" ${ }^{7}$. Este autor diferencia en dos sentidos el respeto a los derechos fundamentales ${ }^{8}$ de la Unión Europea por parte de los Estados miembros mediante:

1. Una interpretación estricta, que fundamenta la vinculación negativa de los Estados miembros a los derechos fundamentales reconocidos en el ordenamiento jurídico europeo cuando aplican el Derecho de la Unión;

2. Y una interpretación amplia, que fundamenta como una actuación está comprendida en el ámbito de aplicación del Derecho de la Unión y en este supuesto los derechos fundamentales reconocidos en el Derecho de la Unión deberán observarse como canon de interpretación de la legalidad nacional.

Finaliza este autor abundando en que estas dos interpretaciones, estricta y amplia, son generalmente confundidas por la Comisión.

\section{Presentación de denuncia ante la Comisión. Las garantías de la fase previa al Recuso por Incumplimiento}

La fase “pre-procesal” de denuncia ante la Comisión desvirtúa su necesario carácter pues repercute en la carencia de tutela judicial efectiva que venimos observando puesto que la vía de denuncia a través de la Comisión es considerada eminentemente administrativa y, aunque presenta ciertas variaciones según se inicie por la Comisión (art. 258 TFUE) o por un Estado miembro (art. 259 TFUE) o aquéllos previstos en el

Estado miembro por incumplimiento del Derecho comunitario frente a los daños sufridos por los particulares, disponiendo desde 1991, cualquier Ciudadano Europeo, la posibilidad de reclamar una indemnización al Estado que infringe una norma comunitaria.

7 MARTÍN DELGADO, I., "El procedimiento administrativo en el Derecho de la Unión Europea”, en Revista de Derecho de la Unión Europea, n 19, 2010, pp. 93 y ss.

${ }^{8}$ En opinión de algunos autores, la Carta de los derechos fundamentales de la UE, alberga un concepto amplio de derechos que no siempre coincide con la idea de estos en las Constituciones de los Estados miembros, pues se carece de una previa fundamentación cultural, y puntualiza que el derecho a una buena administración no es un derecho de los Ciudadanos sino de los administrados, ya sean estos personas físicas o jurídicas, nacionales o extranjeros. GARCÍA ROCA, J., “Originario y derivado en el contenido de la Carta de los Derechos fundamentales de la Unión Europea: los test de constitucionalidad y convencionalidad", en HERRERO DE LA FUENTE, A., (Editor), La Carta de los Derechos fundamentales de la Unión Europea. Una perspectiva pluridisciplinar, Cuadernos del Instituto Rei Afonso Henriques de Cooperación Transfronteriza, nº 1 2, Zamora, 2003, p. 63. 
art. 260 del TFUE en los que se insta al cumplimiento de una sentencia anterior o los propios introducidos por el Tratado de Lisboa (apartado 3 del art. 260) donde la Comisión puede solicitar al Tribunal de Justicia que, ante la falta de comunicación, declare el incumplimiento e imponga el pago de sanciones económicas, todos ellos reciben diversas denominaciones tales como: "procedimiento administrativo previo al Recurso por Incumplimiento", “procedimiento administrativo pre-contencioso” o el "procedimiento de infracción”" , este último término, es como usualmente la Comisión lo refiere.

Hay tres tipos principales de infracción de la legislación de la UE:

- Falta de notificación: cuando un Estado miembro no notifica a tiempo a la Comisión las medidas que adopte para transponer una Directiva;

- No conformidad o incumplimiento: cuando la Comisión considera que la legislación de un Estado miembro no se ajusta a los requisitos de la legislación de la UE;

- Aplicación incorrecta o mala aplicación: cuando las autoridades nacionales no aplican correctamente el Derecho de la Unión o no lo aplican en absoluto.

Las denuncias que se presenten ante la Comisión deberán formularse por cualquier medio escrito (una carta, un fax e incluso por correo electrónico) donde la persona jurídica o física deberá ser muy concreta en lo que respecta a la narración de los hechos imputados al Estado miembro describiendo el estado de las gestiones de denuncia (en el caso de que estas se hubieren iniciado) y la descripción por parte del denunciante de las disposiciones del Derecho de la Unión, que este considera, se hayan infringido.

Este escrito generará un acuse de recibo dentro de los quince días siguientes y se consignará en una base de datos, siendo el documento de denuncia contrario al Derecho de la Unión examinado durante el plazo de un mes para observar si se constituye como tal. En este proceso se ejecutan unas actuaciones previas y, siguiendo el esquema de todo procedimiento sancionador, se desarrolla en dos fases: una primera fase, o fase de investigación, que se lleva a cabo ante la Agencia y una segunda fase, o fase de análisis en cuanto al fondo de los escritos y las denuncias que es competencia de las Direcciones Generales y de los Servicios de la Comisión Europea, como fase de toma de decisiones (procedimiento en sentido estricto) en la que es la Comisión la que interviene.

\footnotetext{
${ }^{9}$ Ver IBAÑEZ GARCÍA, I., "La necesaria regulación del procedimiento de infracción del derecho de la Unión Europea”, Actualidad Administrativa, n 19, 2011, pp. 2 y ss.
} 


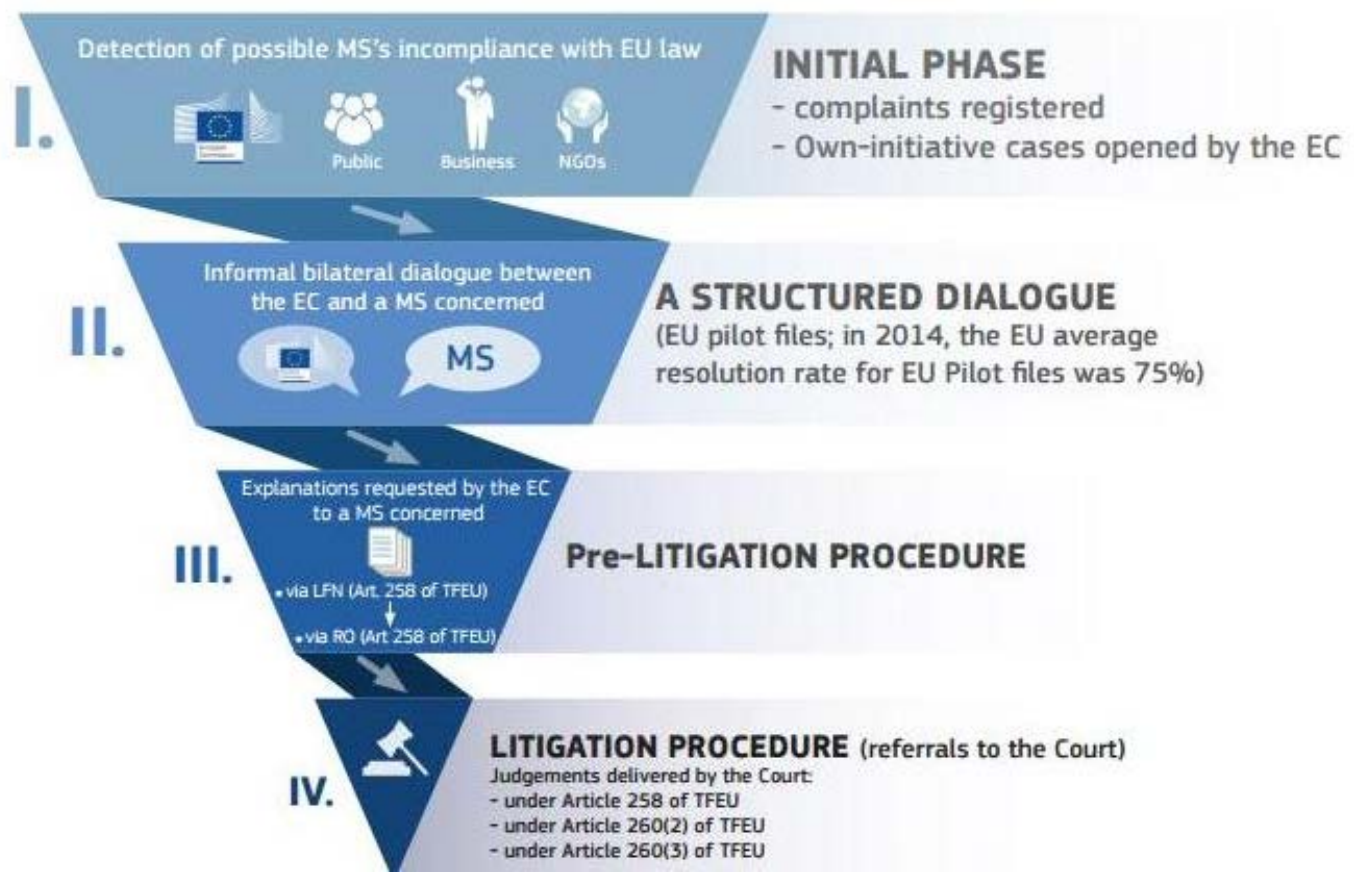

Figura 1 Esquema del procedimiento de Infracción Europeo. Fuente: http://ec.europa.eu/atwork/applying-eulaw/infringements-proceedings/index es.htm Última consulta el 10/06/2016.

El que la doctrina "sin embargo" insista en que en este procedimiento se muestra como un procedimiento administrativo se debe, particularmente, a la ausencia de decisión ejecutiva que ponga fin al mismo ${ }^{10}$ pues, de acuerdo con los Tratados y con carácter general, únicamente el TJUE es el competente para declarar el incumplimiento en que pudiere incurrir el Estado miembro ${ }^{11}$. Pero es evidente que, a pesar de esta máxima, no podemos considerar el procedimiento iniciado por la Comisión de otra forma que no sea un acto administrativo que no debería ser obstáculo a que los diferentes trámites que se realicen en una primera estancia, aun meramente administrativos, deban respetarse las mínimas garantías procedimentales que el ordenamiento jurídico de la Unión reconoce a quienes participan de su desarrollo.

Nuevamente, debe hacerse una excepción cuando el propio ordenamiento jurídico de la Unión alberga la posibilidad en determinados supuestos de incumplimiento el que la propia Comisión, de mutuo propio, sin acudir al TJUE pueda declarar el incumplimiento e imponer la correspondiente sanción. Estas excepciones son los

\footnotetext{
${ }^{10}$ REBOLLO PUIG, M., y BUENO ARMIJO, A., "Los procedimientos administrativos previos al Recurso por Incumplimiento”, en FUERTES, M. (Coord.), Un procedimiento administrativo para Europa, Thomson Reuters- Aranzadi, Navarra, 2012, pp. 343 y 344.

${ }^{11}$ El régimen básico de dichos procedimientos se encuentra en el Tratado de Funcionamiento de la Unión Europea, artículos 258 a 260, así como en distintos instrumentos de soft law, (co-regulación) emitidos por la propia Comisión o el TJUE entre otros, verbigracia; Comunicación de la Comisión sobre la aplicación del artículo 260, apartado 3, del TFUE, SEC (2010) 1371 final, Bruselas, 11.11.2010., o la Comunicación de la Comisión al Consejo y al Parlamento Europeo de actualización de la gestión de las relaciones del denunciante con relación a la aplicación del Derecho de la Unión de 2 de abril de 2012. COM (2012) 154, o comunicación de la Comisión sobre la actualización de los datos para calcular las sumas a tanto alzado y las multas coercitivas que propondrá la Comisión al Tribunal de Justicia en los procedimientos de infracción (2014/C 338/02).
} 
supuestos previstos respecto a las normas sectoriales (art. 108.2 del TFUE) o bien los supuestos de déficit excesivo (art. 126.11 del TFUE) así como las disposiciones que afectan al espacio de libertad, seguridad y justicia ${ }^{12}$. Tanto en estos supuestos como en cualquier otro acto que realice la Comisión, esta, en cuanto se trate de cualquier proceso por incumplimiento y durante el desarrollo del mismo, puede verse satisfecha con la resolución del supuesto estado infractor en su escrito de defensa o bien considerar que se persiste en el incumplimiento, considerando la vía judicial para interponer finalmente el Recurso por Incumplimiento en lo que la doctrina considera un exceso de discrecionalidad por parte de la Comisión en cualquiera de los sentidos.

El procedimiento de infracción que viene descrito en los artículos 258 a 260 TFUE $^{13}$ puede ser iniciado por la Comisión Europea de oficio o como consecuencia de una denuncia o queja de cualquier persona física o jurídica, articulándose igualmente, cuando un Estado encartado no pone fin a un presunto incumplimiento del Derecho de la Unión ${ }^{14}$. Al inicio de un expediente de infracción, la Comisión generalmente recurre a un diálogo ${ }^{15}$ entre los servicios de la Comisión y las autoridades de los Estados

\footnotetext{
${ }^{12}$ SAMPOL PUCURULL, M., "Los procedimientos de infracción. ¿Hay Bases para una Codificación?”, en SORIANO GARCÍA, J, E. (Dir.), Procedimiento Administrativo Europeo, Civitas-Thomson Reuters, Navarra, 2012, pp. 555 a 599.

${ }^{13}$ Artículo 258 TFUE (antiguo artículo 226 TCE): Si la Comisión estimare que un Estado miembro ha incumplido una de las obligaciones que le incumben en virtud de los Tratados, [...] si el Estado de que se trate no se atuviere [...] el plazo determinado por la Comisión, esta podrá recurrir al Tribunal de Justicia de la Unión Europea. Artículo 259 TFUE (antiguo artículo 227 TCE): Cualquier Estado miembro podrá recurrir al Tribunal de Justicia de la Unión Europea, si estimare que otro Estado miembro ha incumplido una de las obligaciones que le incumben en virtud de los Tratados, [...] sometiendo previamente el asunto a la Comisión, [...] la Comisión emitirá un dictamen motivado, una vez que los Estados interesados hayan tenido la posibilidad de formular sus observaciones por escrito y oralmente en procedimiento contradictorio [...]. Artículo 260 TFUE (antiguo artículo 228 TCE): 1) Si el Tribunal de Justicia de la Unión Europea declarare que un Estado miembro ha incumplido una de las obligaciones que le incumben en virtud de los Tratados, dicho Estado estará obligado a adoptar las medidas necesarias para la ejecución de la sentencia del Tribunal. 2) Si la Comisión estimare que el Estado miembro afectado no ha adoptado las medidas necesarias para la ejecución de la sentencia del Tribunal, podrá someter el asunto al Tribunal de Justicia de la Unión Europea, después de haber ofrecido a dicho Estado la posibilidad de presentar sus observaciones, [...] si el Tribunal declarare que el Estado miembro afectado ha incumplido su sentencia, podrá imponerle el pago de una suma a tanto alzado o de una multa coercitiva. [...] 3) Cuando la Comisión presente un recurso ante el Tribunal de Justicia de la Unión Europea en virtud del artículo 258 por considerar que el Estado miembro afectado ha incumplido la obligación de informar sobre las medidas de transposición de una directiva adoptada con arreglo a un procedimiento legislativo, podrá, si lo considera oportuno, indicar el importe de la suma a tanto alzado o de la multa coercitiva que deba ser pagada por dicho Estado y que considere adaptado a las circunstancias [...].

${ }^{14}$ En este segundo supuesto obedece a dos posibilidades, la primera se daría cuando un Estado miembro no notifica dentro del plazo acordado sus medidas nacionales para la transposición de una directiva europea a su ordenamiento jurídico interno. El segundo, cuando la legislación de un Estado miembro no está en consonancia con la legislación de la Unión o cuando las autoridades nacionales no aplican correctamente el Derecho de la Unión.

${ }^{15}$ En los Estatutos del TJUE arts. 23 y 40, se describe como los Estados miembros y las instituciones de la Unión deben coadyuvar en los procesos previstos en los arts. 258 259, 260 del TFUE, justificado en la necesidad de garantizar la efectividad del Derecho de la Unión Europea al objeto de contar con la participación del mayor número de sujetos intervinientes, pero como venimos discutiendo, en el momento de la fijación de la Litis, esta máxima deja de tener sentido para el caso de los particulares
} 
miembros ${ }^{16}$ ("EU Pilot", ${ }^{17}$ que veremos con posterioridad) con el ánimo de facilitar la resolución de problemas de aplicación del Derecho de la UE.

Concluido sin éxito este procedimiento en fase temprana o en los casos en que no recurra al mismo, se pasa a la primera fase o fase administrativa del procedimiento de infracción en la que la Comisión solicita al Estado miembro, a través de una carta de emplazamiento ${ }^{18}$, que este le traslade en un determinado plazo las observaciones que el Estado estima al respecto de la aplicación de determinado Derecho comunitario ${ }^{19}$. En ausencia de respuesta por el Estado encartado, o si esta no fuera satisfactoria para la Comisión, esta elaborará un dictamen que deberá suponerse suficientemente motivado donde la Comisión se pronuncia sobre la infracción y fija el contenido de un posible Recurso por Incumplimiento o instando nuevamente al Estado a que se ponga fin al mismo en el plazo establecido. Respecto al plazo en que la Comisión se compromete a instruir las denuncias registradas, IBÁÑEZ GARCÍA sostiene que situar el plazo máximo dado por la Comisión de un año, es un plazo demasiado extenso máxime cuando no se trata de un plazo para resolver el asunto en cuestión sino es un plazo para únicamente decidirse desde la Comisión, si esta cierra el asunto o si se dirige nuevamente al Estado infractor a través de una carta de emplazamiento ${ }^{20}$. Cabe volver a recordar que la Comisión, en cualquier momento, puede verse satisfecha con la resolución del Estado infractor en su escrito de defensa o bien considerar que se persiste en el incumplimiento considerando la vía judicial para interponer finalmente el Recurso por Incumplimiento, acudiendo la Comisión al Tribunal de Justicia e iniciándose así la fase contenciosa del procedimiento de infracción y solicitando una sentencia que se pronuncie sobre el supuesto incumplimiento.

\footnotetext{
${ }^{16}$ El procedimiento de infracción discurre básicamente entre dos interlocutores, la Comisión y el Estado miembro. Esta bilateralidad entre Comisión-Estado miembro en el procedimiento de infracción puede observarse en la jurisprudencia del TJUE, que, por otra parte, niega el papel de parte a los particulares. Ver Asunto T 191/99, Petriev, Comisión, 2001 II-3677, apartado 70: "En lo que respecta al argumento de los demandantes de que el procedimiento del artículo 226 CE [...], hay que poner de relieve que los particulares no son parte en los procedimientos por incumplimiento y, por tanto, no pueden invocar, como derecho de defensa, la aplicación del principio de contradicción”.

${ }^{17}$ En 2008 la Comisión puso en marcha al Proyecto "EU Pilot” con el afán de mejorarse la comunicación entre la Comisión y los Estados envueltos en cuestiones de aplicación del Derecho de la Unión. En la Resolución del Parlamento Europeo de 4 de febrero de 2014, este define el "EU Pilot" como una plataforma para "debates bilaterales entre la Comisión y el Estado miembro", aduciendo la carencia de un estatuto jurídico que lo regule, por lo que entiende el Parlamento, que únicamente es un instrumento de trabajo en el marco de la autonomía administrativa de la Comisión dentro del procedimiento previo a la infracción, Comisión Europea. "EU Pilot”. Recuperado el 12 de junio de 2016, en

http://ec.europa.eu/internal_market/scoreboard/performance_by_governance_tool/eu_pilot/index_en.htm

${ }^{18}$ La carta de emplazamiento fija el objeto de la posible infracción, así como del ulterior litigio, si lo llegara a haber, por lo que debe contener un detallado informe de la queja y de los elementos necesarios para que el Estado miembro pueda ejercer su defensa, donde el Tribunal de Justicia ha matizado, al respecto de la carta de emplazamiento, que esta no puede someterse a exigencias de precisión tan estrictas como las que se le exige al, sí cabe, posterior dictamen motivado. Así lo han expresado numerosa jurisprudencia, entre otras y para nuestro interés; Vid., Sentencias del Tribunal de Justicia de 18 de mayo de 2006, Comisión c. España, asunto C-221/04, apartado 36.

${ }^{19}$ BACIGALUPO SAGGESE, M., "El sistema jurisdiccional de la Unión Europea”, en Principios de Derecho de la Unión Europea, 6a edición, Colex, Madrid, 2012, p. 543.

${ }^{20}$ IBAÑEZ GARCÍA, I., "El procedimiento pre-contencioso para el control de la aplicación del Derecho comunitario”, en Gaceta jurídica de la Unión Europea y de la competencia, nº 248, 2007, p. 21.
} 
Pronunciada la sentencia en contra del Estado infractor, y en el supuesto que este no ha tomado medida alguna para ejecutar la sentencia en su contra, la Comisión desencadena el procedimiento del artículo 260 del TFUE proponiendo, después de ofrecer nuevamente al Estado la presentación de alegaciones, la imposición de una multa al tribunal que puede ser una cantidad a tanto alzado, como sanción por el incumplimiento en sí, y/o una multa coercitiva, devengada diariamente, mientras no se cumpla la sentencia $^{21}$.

\section{Estudio de caso: La herramienta "EU PILOT" y el cumplimiento por España del Derecho de la Unión}

Desde abril de 2008 se encuentra en funcionamiento el Proyecto “EU Pilot”, puesto en marcha por la Comisión, como herramienta a modo de base de datos que ofrece un canal de comunicación fluido entre el Estado encartado y la Comisión para compartir un sistema especialmente diseñado que ayude a resolver los problemas de cumplimiento, sin poder el Estado que supuestamente haya incurrido en algún incumplimiento eludir el desencadenamiento de un procedimiento de infracción pero ofreciendo a los Estados miembros la oportunidad de subsanar los posibles incumplimientos de manera voluntaria. La siguiente infografía resume las distintas fases del procedimiento "EU Pilot”, donde se han trasladado el último informe de julio de 2015:

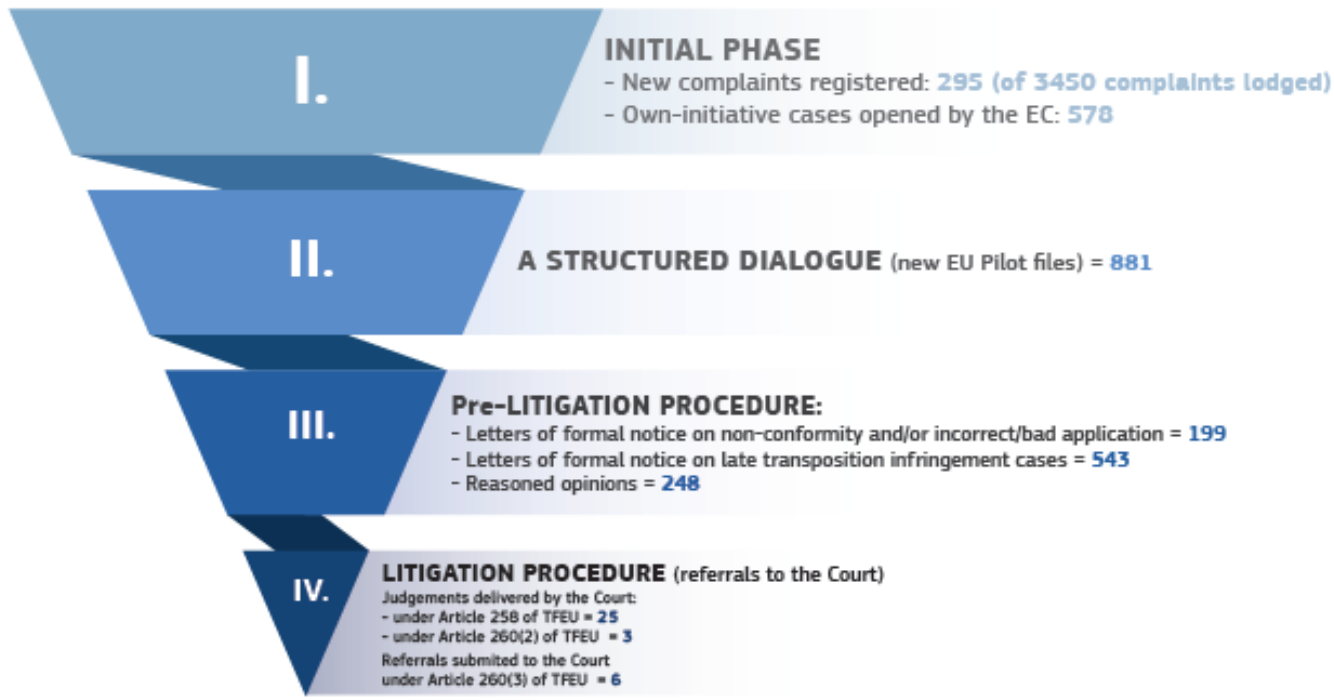

Figura 2 Esquema del procedimiento Pilot. Fuente: http://ec.europa.eu/atwork/applying-eu-law/infringementsproceedings/index_es.htm Última consulta el 10/06/2016.

\footnotetext{
${ }^{21}$ COMUNICACIÓN DE LA COMISIÓN Actualización de los datos para calcular las sumas a tanto alzado y las multas coercitivas que propondrá la Comisión al Tribunal de Justicia en los procedimientos de infracción 2014/C 338/02. La Comisión aplicará las siguientes cifras actualizadas para calcular el importe de las sanciones financieras (suma a tanto alzado o multa coercitiva) cuando someta el asunto al Tribunal de Justicia en virtud del artículo 260, apartados 2 y 3 del TFUE:

1) el tanto alzado de base uniforme para el cálculo de la multa coercitiva se fija en 660 EUR diarios;

2) el tanto alzado de base uniforme para el pago de la suma a tanto alzado se fija en 220 EUR diarios; España; Factor especial $(12,72)$ Suma a tanto alzado mínima para España (7.015). Recuperado el 1 de junio de 2016, en http://eur-lex.europa.eu/legalcontent/ES/TXT/?uri=uriserv:OJ.C_.2014.338.01.0018.01.SPA
} 
En el funcionamiento del Proyecto “EU Pilot”, la Comisión Europea actúa como guardián ${ }^{22}$ del Tratado y supervisa la aplicación de la legislación de la UE bajo la supervisión de la corte del TJUE. En este esquema del procedimiento "EU Pilot" (figura 2), la Comisión Europea podrá tomar una acción si un Estado miembro:

- No incorpora plenamente las directivas de la UE (518 casos estaban abiertos a finales de 2015) a tiempo en su legislación nacional o no ha comunicado a la Comisión que medidas ha adoptado para este fin;

- O se supone que ha adoptado disposiciones que no están en conformidad con el Derecho de la Unión o están mal aplicadas en su transposición (850 casos estaban abiertos a finales de 2015).

En el año 2014, el número de nuevas denuncias presentadas contra España aumentó en más de una centena en relación con el año 2013. A pesar de este aumento, es todavía inferior a los datos que España mostraba situándose el país en una tendencia a la baja que se inicia en 2011. En la mayoría de los casos, España incurre en procedimientos de infracción por transposición tardía. En el trigésimo tercer informe anual sobre el control de la aplicación del Derecho de la Unión hecho público por la Comisión Europea en 2015, España ha reducido los procedimientos de infracción en su contra por transposiciones incorrectas o tardías de las directivas de la Unión, logrando así alcanzar el menor nivel hasta el momento en los últimos cinco años. Este logro, sin embargo, se ve frustrado cuando España se sitúa como uno de los tres países más incumplidores de la Unión. Según este informe, en 2015 España sufrió 21 infracciones por transposición tardía y 83 por transposición incorrecta y/o mala aplicación del Derecho de la Unión. Particularmente en España en 2015 se abrieron 37 procedimientos de infracción por transposición incorrecta (en materias dispares como por ejemplo; el medio ambiente; la movilidad y los transportes; la estabilidad financiera, los servicios financieros y los mercados de capitales y el mercado interior), a su vez se abrieron igualmente 16 procedimientos por transposición tardía (en ámbitos como: la estabilidad financiera; también la movilidad y transportes; e igualmente el mercado interior y como novedad la migración). En la siguiente infografía, podemos observar el número total de casos abiertos por cada Estado miembro, viendo situada a España en tercer lugar por detrás de Italia y Alemania. La columna azul del diagrama se refiere a las infracciones por transposición incorrecta y o una mala aplicación del Derecho de la Unión donde observamos a España con 83 casos abiertos mientras que la columna verde refiere las infracciones por transposición tardía, donde España tiene aperturados 21 casos.

\footnotetext{
${ }^{22}$ En la Resolución de 4 de febrero de 2014, del Parlamento Europeo "este acoge con satisfacción el hecho de que, gracias al uso del método del proyecto piloto ("EU Pilot”) se hayan acortado los plazos necesarios para la investigación de presuntas infracciones, pero se muestra reticente con la política de la Comisión, al no ofrecer una mayor información y aclaración del funcionamiento de la herramienta, a fin de que las instituciones de la Unión y el propio Parlamento puedan juzgar el funcionamiento de este método desde el punto de vista de su cumplimiento efectivo por los Estados miembros”.
} 


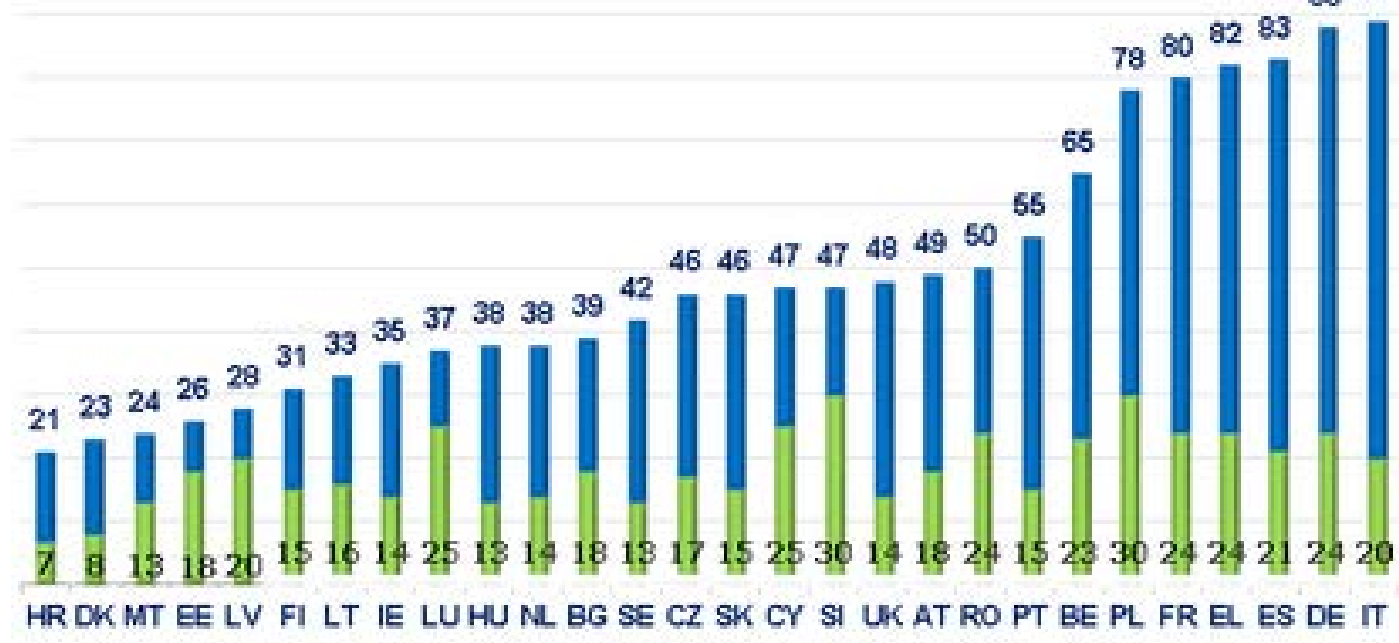

Figura 3 Número de casos de infracción abiertos en la UE a 31 de diciembre de $2015 . \quad$ Fuente: http://europa.eu/rapid/press-release_IP-16-2245_es.htm Última consulta el 10/06/2016.

Las generalidades de los casos de infracción se reparten según la distribución de la siguiente infografía (figura 4) facilitada por la Comisión a través de "EU Pilot” donde en los distintos países de la Unión los casos con relación al medio ambiente y al transporte son los que más incidencias presentan.

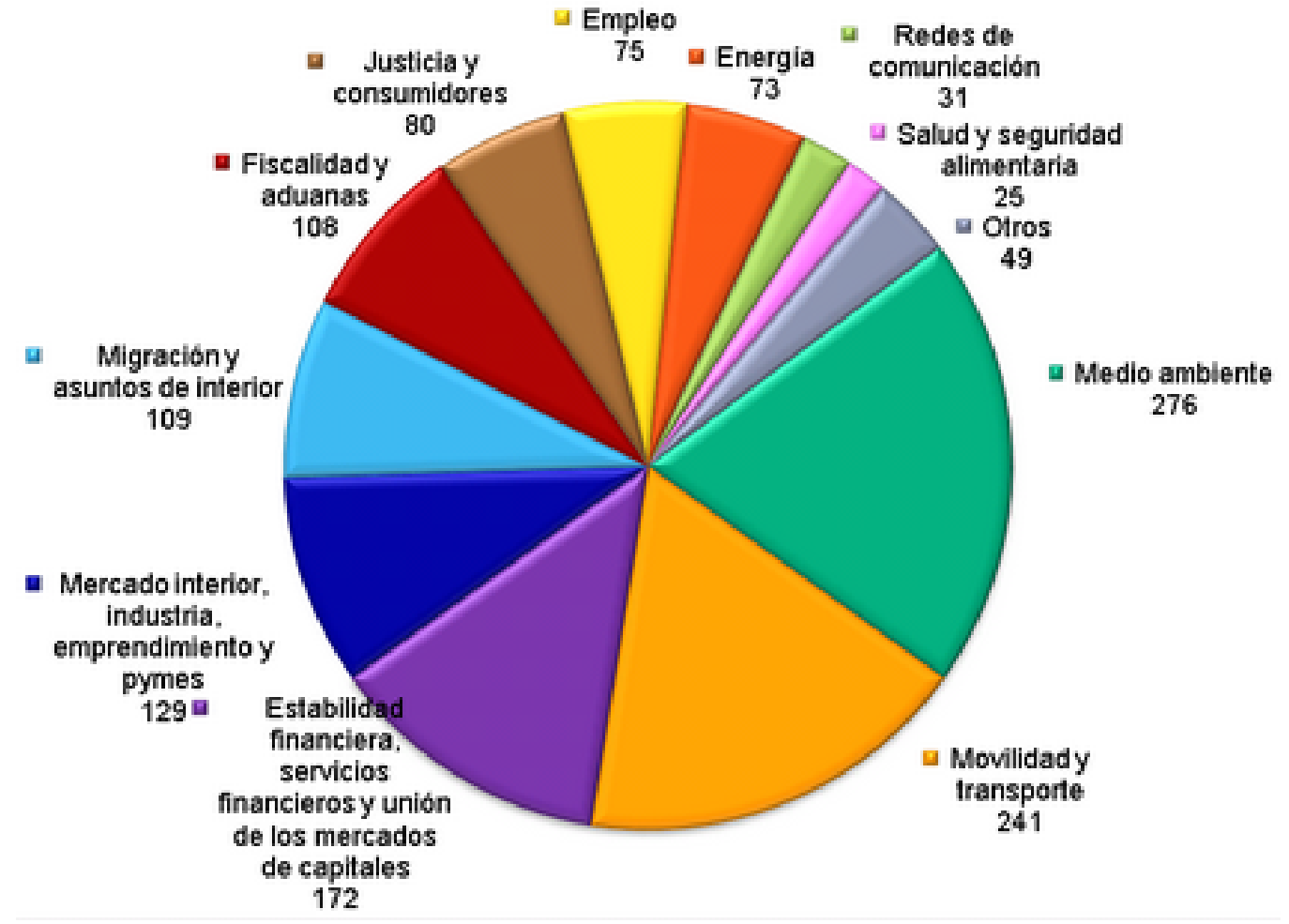

Figura 4 Número de casos de infracción abiertos a 31 de diciembre de 2015. Fuente: http://europa.eu/rapid/pressrelease IP-16-2245 es.htm Última consulta el 14/06/2016. 
En España, como ya ocurría en el año 2014, los casos sobre el medio ambiente y el transporte siguen siendo los ámbitos de actuación con más casos de infracción abiertos en 2015 (Figura 5).

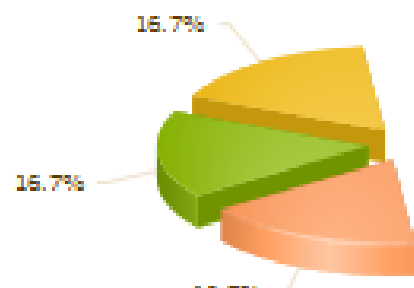

16.726
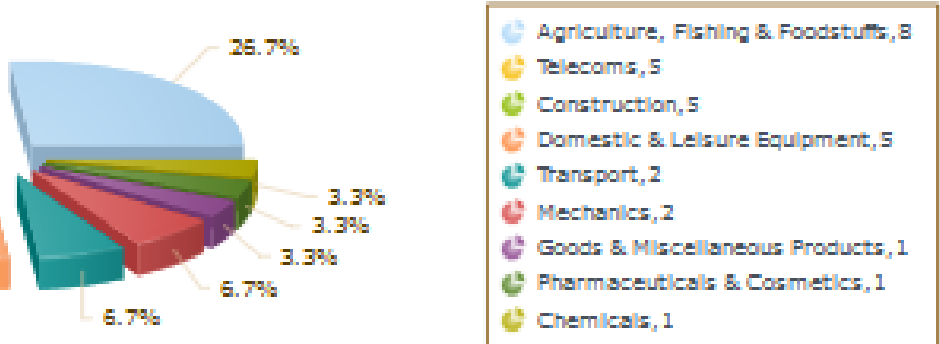

Figura 5 Número de casos de infracción abiertos a España a 31 de diciembre de $2015 . \quad$ Fuente: http://europa.eu/rapid/press-release IP-16-2245 es.htm Última consulta el 21/06/2016.

En la siguiente infografía observamos en perspectiva el déficit de transposiciones por parte de España desde 1997 hasta diciembre de 2015 donde finalmente se arroja el déficit de transposición: 0.4\%, mientras que, en el informe del año anterior, España arrojaba un déficit del $0.8 \%$, teniendo en cuenta que la media de déficit en la Unión es del $0.7 \%$.

La demora de la resolución de las infracciones sobre España, donde habitualmente se tomaba de media 11.5 meses, en el último informe este dato mejora cuantitativamente situándose la demora en la resolución de los casos para España en 5.1 meses. Esta demora podría tener como causa que la mitad de las directivas pendientes de España (2 de cada 4) tienen más de un año de retraso, lo que implica que las antiguas directivas pendientes afectan a la ratio general como resultado. En España todavía son 11 las directivas que aún no se han adaptado correctamente a la legislación nacional.

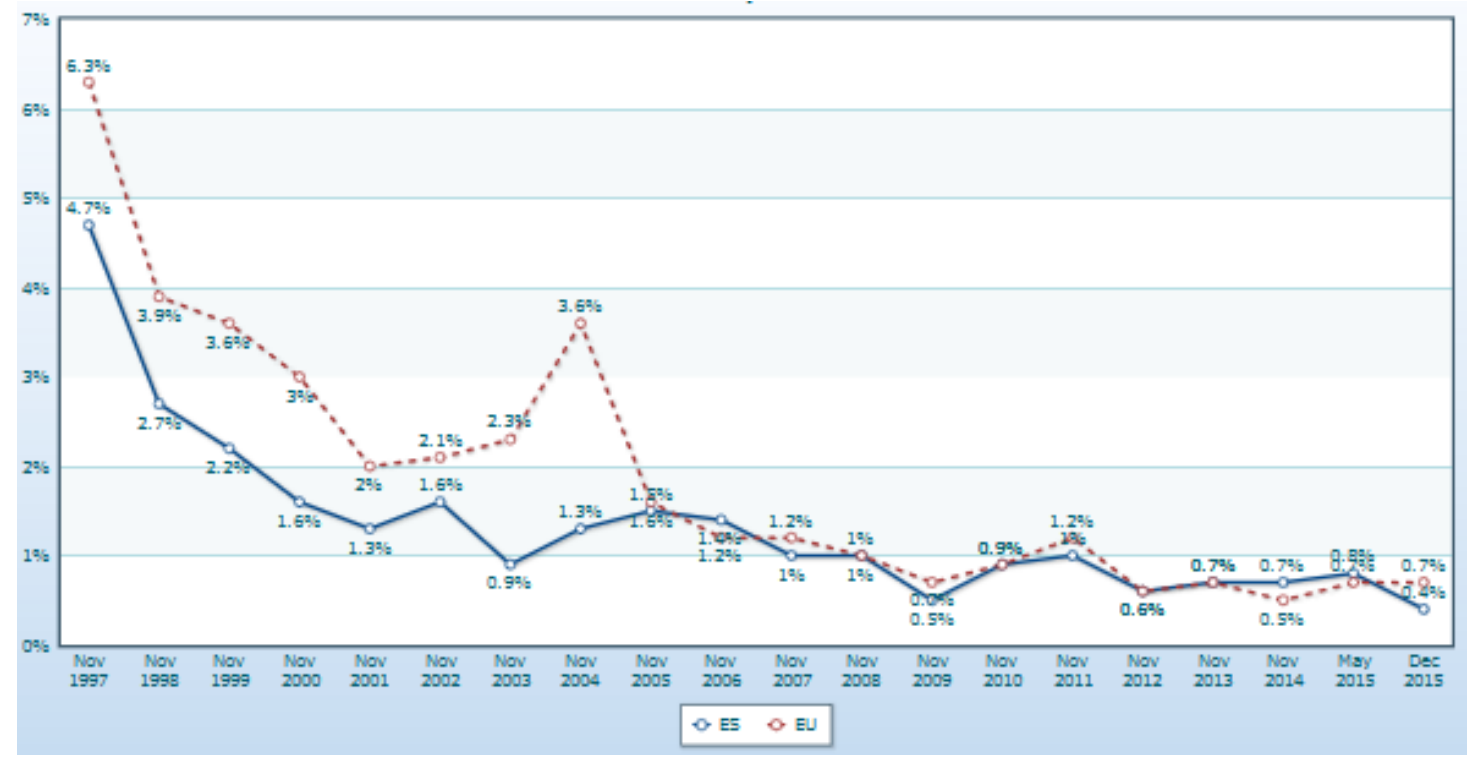

Figura 6 Número de casos de infracción abiertos a España al 31 de diciembre de 2015. Fuente: http://ec.europa.eu/internal_market/scoreboard/performance_by_member_state/spain/index_en.htm Última consulta el 10/06/2016. 
La evolución de las infracciones sobre España se observa en la siguiente infografía correspondiendo al año 2015: la apertura de 10 nuevos casos y también el cierre de otros 10 casos, arrojando el último informe 50 casos pendientes y mostrando este resultado una tendencia estable entre los 6 Estados miembros con la mayoría de las infracciones relacionadas con el mercado único, donde la media por los Estados se sitúa en 26 casos. En España, los sectores que presentan mayores colisiones con la normativa de la Unión son: el medio ambiente, entendido como impacto ambiental (con 5 casos) y la protección del agua y la gestión (con 5 casos); los impuestos directos e indirectos (con 6 casos); los derechos y condiciones de trabajo (también con 6 casos); y cuestiones sobre el transporte aéreo (con 5 casos). La duración media de los casos incursos por España son 21.4 meses, situándose España como uno de los 8 países que más han reducido la duración media de los casos, estando situada esta media europea en 30.7 meses. El cumplimiento de las resoluciones judiciales en los casos en que la corte llega a intervenir se sitúa para España en 20.1 meses siendo la media de la Unión en 21 meses (Figura 7).

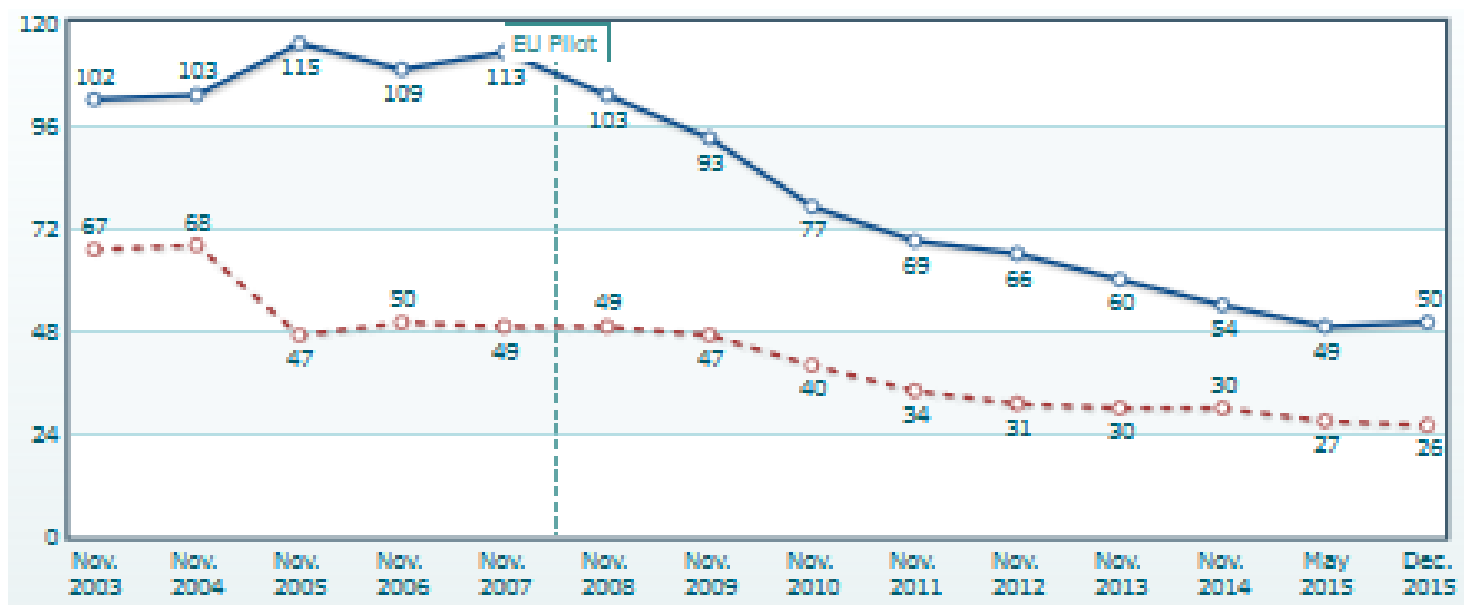

Figura 7 Número de casos pendientes de resolución abiertos a España al 31 de diciembre de 2015. Fuente: http://ec.europa.eu/internal market/scoreboard/performance by member state/spain/index en.htm Última consulta el 10/06/2016.

\section{III.- LA CUESTIÓN PREJUDICIAL}

Como venimos describiendo, las administraciones de los Estados miembros se someten al Derecho de la Unión una vez que este se ha incorporado al ordenamiento jurídico del Estado, obligándose los jueces nacionales a colaborar con el TJUE velando por el respeto ante cualquier vulneración en la aplicación de los principios generales del Derecho europeo que pudiera ser fiscalizable por el TJUE. A este respecto, SAIZ ARNAIZ efectúa una descripción de las actuaciones fiscalizables por el Tribunal y deben ser respetadas por los órganos jurisdiccionales de los Estados ${ }^{23}$ : "a) las

\footnotetext{
${ }^{23}$ La sentencia Vaassen-Göbbels (STJ de 30.6.1966, asunto 61/65) señaló que hay que considerar como órgano jurisdiccional a todo organismo permanente que esté constituido conforme a la legislación nacional, con competencia vinculante y que esté sometido a normas de procedimiento contradictorio para aplicar normas jurídicas.
} 
intervenciones en ejecución de las normas comunitarias; b) la normativa de transposición de directivas; c) las derogaciones o excepciones al ordenamiento comunitario por él permitidas; y d) las normas internas que interfieran con algunos principios generales del Derecho comunitario" ${ }^{24}$, siendo los órganos jurisdiccionales previstos en los Tratados los que vienen garantizando los derechos ordinarios o fundamentales, ${ }^{25}$ mediante el Recurso de anulación, el Recurso de incumplimiento, el Recurso por omisión, así como la excepción de ilegalidad y la Cuestión Prejudicial de Validez y la Cuestión Prejudicial de Interpretación. En este epígrafe nos ocuparemos de la Cuestión Prejudicial.

La Cuestión Prejudicial articula un procedimiento de cooperación judicial entre el TJUE y los órganos jurisdiccionales de los Estados miembros, procediendo su planteamiento cuando en un litigio en sede de un tribunal de un Estado miembro resulte aplicable una disposición de Derecho de la Unión sobre cuya interpretación se pudiere albergar una duda razonable o cuya validez sea cuestionable y donde el tribunal nacional, según el caso, podrá suspender el procedimiento y solicitar el pronunciamiento sobre determinada cuestión al TJUE, resolviendo el tribunal nacional a la luz del pronunciamiento del TJUE.

La doctrina coincide que la Cuestión Prejudicial se muestra entonces como un accidente procesal incurso en un procedimiento principal sustanciado básicamente en sede judicial de un Estado miembro.

\section{Cuestión Prejudicial de Interpretación y Validez}

La Cuestión Prejudicial de Interpretación se sustancia ante la cuestión planteada por el tribunal nacional, interpelando al TJUE en aras a que este emita su pronunciación sobre el sentido y alcance ${ }^{26}$ de una determinada disposición del Derecho de la Unión relativa,

\footnotetext{
${ }^{24}$ SAIZ ARNAIZ, A., "La Carta de los Derechos Fundamentales de la Unión Europea y los ordenamientos nacionales", Cuadernos de Derecho Público, núm. 13, 2001, p. 156.

${ }^{25}$ No existe en el ordenamiento jurídico europeo un cauce específico que permita al particular alegar la violación de los derechos fundamentales ejercitable por los particulares ante el TJUE, citado en FERNÁNDEZ TOMÁS, A., La Carta de Derechos fundamentales de la Unión Europea, Tirant lo Blanch, Valencia, 2001, p. 149.

${ }^{26}$ Se presentan distintas excepciones si el TJUE se hubiere pronunciado previamente sobre la interpretación de la disposición de Derecho de la Unión, tales como el "acto aclarado” y "el acto claro” y el tribunal nacional quiere apartarse de dicha interpretación, siendo obligatoria en este caso desencadenar la Cuestión Prejudicial. La doctrina del "acto aclarado" discurre cuando el TJUE ha tenido la ocasión de interpretar la cuestión planteada en pronunciamientos previos, independientemente que estos tengan o no similar naturaleza, y el tribunal nacional pretenda apartarse de la esta jurisprudencia (Sentencia 27.3.1963, asuntos acumulados 28, 29, 30/62, caso Da Costa). Mientras que la doctrina del "Acto Claro" se sustancia cuando la correcta aplicación del Derecho de la Unión se impone de manera tan evidente ante el órgano jurisdiccional nacional, que no queda lugar duda alguna sobre la manera de resolver la cuestión suscitada” (Sentencia, del TJCE 1982, asunto 283/81, Cilfit). En cualquier caso, esta posibilidad de juzgar la "claridad" de la norma se ve restringida por el mismo Tribunal: "antes de llegar a tal conclusión, el órgano jurisdiccional debe estar convencido de que la misma evidencia se impondrá igualmente a los órganos jurisdiccionales nacionales de los otros Estados miembros y al Tribunal de Justicia, de forma que sólo si se cumplen estos requisitos, el órgano jurisdiccional nacional podrá abstenerse de someter la cuestión al Tribunal y resolverla bajo su propia responsabilidad".
} 
entre otras, al Derecho originario, Derecho derivado, Derecho primario consuetudinario, cualquier acto típico o atípico de las instituciones de la Unión, acuerdos internacionales, sentencias discurridas en sede del TJUE etc., y que una vez emitida la sentencia, tiene alcance general erga omnes.

La Cuestión Prejudicial de Validez es un mecanismo para observar un control indirecto de la legalidad de los actos del Derecho de la Unión ${ }^{27}$ de modo que se articula cuando el tribunal de un Estado miembro interpela al TFUE sobre la validez de una disposición del Derecho de la Unión que debe ser aplicable al litigio que este está resolviendo. Tiene la limitación de no poder articularse en cuestiones referentes al Derecho originario, sometiendo únicamente a los actos de los organismos de la Unión y los acuerdos internacionales. Además, tiene la virtud de ayudar a superar la legitimización activa de los particulares que se ve limitada en los recursos de anulación ${ }^{28}$. Tal como señala PESCATORE, la Cuestión Prejudicial sería así como el procedimiento de infracción del Derecho de la Unión Europea para los Ciudadanos ${ }^{29}$. Respecto a la procedencia y disposición de la Cuestión Prejudicial por los órganos jurisdiccionales de los Estados miembros, es necesario que se plantee exclusivamente ante la interpretación o validez de una disposición del Derecho de la Unión dentro de un procedimiento que se está sustanciando en sede del tribunal nacional y que necesita el auxilio del TJUE en aras de su resolución. Sin embargo, no siempre el TJUE entra a valorar la oportunidad de la Cuestión Prejudicial negándose generalmente a resolver cuestiones:

- Que no se susciten en el marco de un litigio real;

- Que en el caso que sí sea un litigio real, la cuestión planteada no guarde relación con el marco del litigio principal;

- Que en el caso planteado por el órgano jurisdiccional del Estado miembro, en su planteamiento este esté insuficientemente motivado;

- Que la normativa a aplicar fuere manifiestamente inaplicable o no guarde relación el planteamiento con el Derecho de la Unión.

\footnotetext{
${ }^{27}$ Los tribunales nacionales no disponen de la facultad de declarar inválidos los actos de las instituciones comunitarias, pues solo tienen la potestad de formular juicios positivos de validez, estimando si el acto de Derecho de la Unión aplicable al litigio principal que ha de resolver si fuere válido, si se consideran fundados los motivos de invalidez que las partes alegan, están obligados en todo caso (sean o no recurribles sus resoluciones) a plantear Cuestión Prejudicial de Validez ante el TJUE, como Fumus boni iuris o Periculum in mora (Sentencia TJCE 1987, Foto-Frost), decayendo esta obligación si existiere un pronunciamiento anterior del TJUE en el que declara la invalidez del acto de Derecho de la Unión que se cuestiona (Sentencia TJCE 1981, International Chemical Corporation)

${ }^{28}$ Uno de los medios jurisdiccionales más importantes del Contencioso de la Unión Europea es el Recurso de anulación, como un instrumento de base, que fortalece la legalidad del ordenamiento jurídico comunitario y asume la garantía jurisdiccional de los sujetos que encarnan los intereses de la Unión. FARAMIÑÁN GILBERT, J.M. de: "El Control de la Legalidad Comunitaria: El Recurso de nulidad y el Recurso por omisión”, El Derecho Comunitario Europeo y su Aplicación Judicial, (dirigida por Dr. G. C. RODRÍGUEZ IGLESIAS y Dr. D. J. LIÑÁN NOGUERAS), ed. Civitas, Madrid, 1993, p. 454 señala "Incluso, más allá de las influencias recibidas del contencioso administrativo francés o alemán, resulta claro que la especificidad del derecho comunitario ha buscado soluciones propias adaptadas a sus características".

${ }^{29}$ PESCATORE, P., "Van Gend en Loos, 1963. A view from within”, en POIARES MADURO, M. and AZOULAI, L. (Eds.). The Past and the Future of EU Law. The Classics of EU Law revisited on the 50th Anniversary of the Rome Treaty, Hart Publishing, Portland, 2010, p. 7.
} 
Respecto a los plazos ${ }^{30}$ que dispone el TJUE, este goza de una discrecionalidad tal, que no establece plazo alguno para su resolución. Ha sido desde el Tratado de Lisboa cuando se emite alguna referencia en cuanto a la dilación de su consulta pero solamente cuando el encartado en el asunto que se esté dirimiendo tenga relación con una persona que se encuentre privada de libertad.

\section{La omisión de la Cuestión Prejudicial}

Tenemos que interconectar en este epígrafe la posible omisión de la Cuestión Prejudicial antes de adelantar el capítulo final donde analizaremos conjuntamente con el Recurso por Incumplimiento ambas herramientas, al objeto de conectar la deriva que puede tomarse ante la omisión que los tribunales de última instancia de un Estado miembro incumplan la obligación señalada en el artículo 234.3 de elevar una Cuestión Prejudicial al Tribunal de Justicia de la Unión Europea.

Según LÓPEZ DALLARA ${ }^{31}$, la cuestión a observar, y que surge al presentarse la vía del Recurso por Incumplimiento por parte de la Comisión ante la omisión de los tribunales de elevar la Cuestión Prejudicial ante el TJUE, versa sobre si esta ejecución de la Comisión, desencadenando el procedimiento por incumplimiento con el ánimo de fiscalizar la potestad de un órgano jurisdiccional de última instancia de un Estado miembro, redunda o contribuye, en palabras de la autora, a un mejor funcionamiento del sistema jurisdiccional de la Unión y a su vez no se intervenga o interfiera el principio de independencia judicial.

Ante esta circunstancia se ha pronunciado el Tribunal Constitucional sobre la posible vulneración del Derecho de la Unión por una autoridad judicial de las que anteriormente

\footnotetext{
${ }^{30}$ Artículo 267 (antiguo artículo 234 TCE): El Tribunal de Justicia de la Unión Europea será competente para pronunciarse, con carácter prejudicial:

a) Sobre la interpretación de los Tratados;

b) Sobre la validez e interpretación de los actos adoptados por las instituciones, órganos u organismos de la Unión cuando se plantee: Una cuestión de esta naturaleza ante un órgano jurisdiccional de uno de los Estados miembros, dicho órgano podrá pedir al Tribunal que se pronuncie sobre la misma, si estima necesaria una decisión al respecto para poder emitir su fallo; Una cuestión de este tipo en un asunto pendiente ante un órgano jurisdiccional nacional, cuyas decisiones no sean susceptibles de ulterior recurso judicial de Derecho interno, dicho órgano estará obligado a someter la cuestión al Tribunal; y Una cuestión de este tipo en un asunto pendiente ante un órgano jurisdiccional nacional en relación con una persona privada de libertad, el Tribunal de Justicia de la Unión Europea se pronunciará con la mayor brevedad.

${ }^{31}$ LÓPEZ DALLARA, M, L. "Recurso por Incumplimiento y responsabilidad de los Estados miembros por actos de sus órganos judiciales en violación de la obligación impuesta por el artículo 234.3 TCE”. En palabras de la autora: La Comisión ha permanecido al margen ante la circunstancia de que los órganos jurisdiccionales cuyas decisiones no son susceptibles de ulterior recurso judicial de Derecho interno no eleven el reenvío prejudicial ante el TJCE, con base en que, el Recurso por Incumplimiento como mecanismo para evitar el no planteamiento de reenvío prejudicial por los órganos jurisdiccionales obligados a ello, no resulta una herramienta adecuada, toda vez que, puede derivar en interferencias a la independencia de los jueces estatales. Recuperado el 18 de mayo de 2016, en http://noticias.juridicas.com/conocimiento/articulos-doctrinales/4518-recurso-por-incumplimiento-yresponsabilidad-de-los-estados-miembros-por-actos-de-sus-organos-judiciales-en-violacion-de-laobligacion-impuesta-por-el-articulo-234-3-tce/
} 
hemos enumerado. Según este, la negativa de un tribunal a plantear la Cuestión Prejudicial ante el TJUE no debe considerarse un hecho de carácter constitucionalmente relevante, dado que no cabe amparo, frente a normas dictadas por las instituciones de la Unión, sino únicamente contra disposiciones, actos jurídicos o simples vías de hecho de los poderes públicos internos que lesionen los Derechos Fundamentales y libertades públicas enunciadas en los artículos 14 a 30 de la Constitución, con exclusión de las eventuales vulneraciones del Derecho Comunitario ${ }^{32}$. En este sentido, entiende el Tribunal Constitucional que la carencia de solicitud de una Cuestión Prejudicial no es susceptible de generar directamente una vulneración de la tutela judicial efectiva, puesto que la vulneración del art 267 (antiguo artículo 234 TCE) no consiste en sí misma en una vulneración de la Constitución Española ya que esta disposición pertenece al ámbito del Derecho Comunitario y no constituye, por sí misma, canon de constitucionalidad alguno. La decisión de plantear la Cuestión Prejudicial es una decisión exclusiva e irrevisable del órgano judicial y no hay vulneración de un Derecho Fundamental recogido en la Constitución cuando el juez razonadamente no alberga duda sobre la norma comunitaria, lo que hace innecesario el planteamiento ante el TJUE, pues enjuiciar la selección normativa del juez que excluye la aplicación del Derecho Comunitario estimando aplicable la normativa nacional no es competencia del TC.

Una vez realizada esta breve descripción de la Cuestión Prejudicial y sus distintas particularidades y una vez descritas en los anteriores epígrafes las peculiaridades del Recurso por Incumplimiento, pasamos ahora a realizar el estudio entre las diferencias y las similitudes de estos dos mecanismos, así como la valoración por nuestra parte de la tutela que ejercen sobre el Derecho de la Unión.

\section{IV.- CUESTIONAMIENTO DE LA TUTELA DEL DERECHO DE LA UNIÓN EUROPEA MEDIANTE LOS MECANISMOS DEL RECURSO POR INCUMPLIMIENTO Y LA CUESTIÓN PREJUDICIAL}

Hemos descrito en anteriores epígrafes cómo se diferencian meridianamente la Cuestión Prejudicial y el Recurso por Incumplimiento previsto en los artículos 258 a 260 del TFUE (antiguos 226 a 228 TCE), pero ambos mecanismos se asemejan en que pueden desencadenar una sentencia del TJUE y que esta sentencia declare en un mismo sentido, independientemente del cauce iniciado, la incompatibilidad de una determinada normativa de un Estado miembro con respecto al Derecho de la Unión. En Sentencia del propio TJUE en el asunto Humblet ${ }^{33}$, este se declara incompetente ya resuelva una Cuestión Prejudicial o un Recurso por Incumplimiento para anular un acto legislativo de un Estado miembro, indicando el TJUE que serán los Estados miembros quienes

\footnotetext{
32 Origen y evolución histórica: "De las CCEE a la UE. La dinámica del proceso de integración: Ampliación vs profundización. La ampliación (adhesiones pasadas y futuras), la profundización (etapas y perspectivas), el carácter abierto, pero (políticamente) irreversible del proceso de integración”, recuperado el 12 de mayo de 2016 en http://e.exam-10.com/pravo/14415/index.html?page=21

33 Asunto 6/60, Humblet, Rec. 1960 01125. Citado en GARCÍA ANTÓN, R., "La Cuestión Prejudicial y la fiscalidad directa". Thesis submitted for assessment with a view to obtaining the degree of Doctor of Laws of the European University Institute Florence, Dir. Dr. Loïc Azoulai, 30 April 2015, pp 163 y ss.
} 
deberán adoptar las medidas necesarias para la ejecución de las sentencias ${ }^{34}$. Respecto a la Cuestión Prejudicial y en palabras de GARCÍA ANTON, el TJUE puede delegar la resolución de la Cuestión Prejudicial en el órgano jurisdiccional remitente del Estado miembro o bien eludir la contestación dejando la cuestión abierta, aludiendo el citado autor que estaríamos en lo que se denomina usualmente como open-ended cases. Esta posibilidad o supuesto no sucede cuando se trata de Recursos por Incumplimiento ya que el tribunal siempre se pronuncia de manera expresa al respecto de la oposición o no de la normativa nacional con relación a la normativa de la Unión, emitiendo un fallo concreto que aclara si el Estado miembro ha incumplido o no sus obligaciones respecto a los Tratados asumidos ${ }^{35}$.

Debemos hacernos cargo en este epígrafe final que las sentencias emitidas a través de estos dos mecanismos comprenden una vocación erga omnes, desplegando sus efectos "frente a todas" las jurisdicciones nacionales, obligándose estos a darles cumplimiento.

En relación con el Recurso por Incumplimiento, el TJUE indica cómo el Estado miembro deberá abstenerse de manera inmediata en la aplicación de la norma declarada incompatible, debiendo adoptar las medidas necesarias para restaurar la aplicación del Derecho de la Unión ${ }^{36}$. En el caso de una Cuestión Prejudicial, no se recoge de manera expresa en la sentencia que el Estado miembro esté obligado o sometido a abstenerse de aplicar cualquier norma que resulte incompatible con el Derecho de la Unión debido a que, en este caso y mientras no se contemple la situación que anunciábamos como openended cases, la sentencia emitida contempla un único destinatario siendo este el órgano jurisdiccional que formuló la cuestión, independientemente que esta respuesta y aplicación contenga un lógico efecto, como señala el propio GARCIA ANTON, de "radiación” sobre el ordenamiento jurídico del Estado miembro del mismo modo y alcance en el caso de una sentencia que resuelva un Recurso por Incumplimiento. La

\footnotetext{
${ }^{34}$ En la sentencia Comisión con Italia (STJCE: Caso C-129/00 Comisión c. República Italiana, del 9 de diciembre de 2003), el Abogado General GEELHOED se reafirmó en que "el Estado miembro responde considerado como una unidad del cumplimiento de las obligaciones comunitarias y que es responsable de cualquier incumplimiento, al margen del órgano que lo haya cometido dentro de la organización interna del Estado, incluido el poder judicial. Corresponde al Estado miembro como entidad autónoma velar por la realización en el ordenamiento jurídico nacional del resultado perseguido por las normas comunitarias correspondientes. Así se desprende asimismo del principio de lealtad comunitaria establecido en el artículo 10 TCE.” Conclusiones del Abogado General GELHOED: Caso C-129/00 Comisión c. República Italiana, del 9 de diciembre de 2003, Parágrafo 55. Citado en LÓPEZ DALLARA, M, L. "Recurso por Incumplimiento y responsabilidad de los Estados miembros...” ob. cit., en http://noticias.juridicas.com/conocimiento/articulos-doctrinales/4518-recurso-por-incumplimiento-yresponsabilidad-de-los-estados-miembros-por-actos-de-sus-organos-judiciales-en-violacion-de-laobligacion-impuesta-por-el-articulo-234-3-tce/

${ }^{35}$ GARCÍA ANTÓN, R., La Cuestión Prejudicial y la fiscalidad directa... ob. cit., p. 163

${ }^{36}$ En el caso Brasserie du Pêcheur, Conclusiones del Abogado General TESAURO C-46/93 y 48/93 [1996] R. I 1029 cdo 35 y 38, se hizo referencia al principio según el cual el Estado, como sujeto de Derecho Internacional, debe contemplarse como una entidad única a los efectos de determinar la responsabilidad internacional por violaciones de las normas de Derecho Internacional, siendo irrelevante qué poder del Estado, legislativo, ejecutivo o judicial, haya sido el origen del ilícito que causa la responsabilidad, ocurriendo según el Abogado General, que con mayor razón en el ordenamiento jurídico comunitario, "donde todas las instancias del Estado, incluso el poder legislativo, están obligadas, en el cumplimiento de sus funciones, a respetar las normas impuestas por el Derecho comunitario que pueden regir directamente la situación de los particulares”.
} 
única diferencia que podríamos considerar en este caso entre ambos procedimientos, con carácter sustancial, tendría lugar en el supuesto que no exista un cumplimiento espontáneo de cualquiera de las sentencias recibidas por parte del TJUE. Notable diferencia nos encontramos en las medidas que pueden desencadenarse en el caso del Recurso por Incumplimiento que se sustancian a tenor del art. 260.2, donde la Comisión tiene la atribución de poder dirigirse al TJUE para exigir la imposición de sanciones económicas $^{37}$ y que no se contempla para el caso de plantearse la Cuestión Prejudicial en los supuestos en los que el órgano jurisdiccional nacional no cumpla con el dictamen del TJUE.

\section{La discrecionalidad como elemento subyacente en los mecanismos del Recurso por Incumplimiento y la Cuestión Prejudicial}

El control de la efectividad del Derecho de la Unión que realiza el TJUE a través de las herramientas de la Cuestión Prejudicial o el Recurso por Incumplimiento se amparan en una desmedida discrecionalidad para ser esta iniciada independientemente ya sea la Comisión o el Órgano Jurisdiccional el encargado de promoverlas.

Tal y como señala GARCÍA ANTÓN ${ }^{38}$, pese a que la Cuestión Prejudicial y el Recurso por Incumplimiento velen por la efectividad del Derecho de la Unión, son notables y evidentes las diferencias de ambos mecanismos en cuanto a su fundamentación, pues si consideramos a la Cuestión Prejudicial como mecanismo procesal vinculado a la protección de la tutela judicial efectiva garante de los derechos que el Derecho de la Unión otorga a los individuos, el Recurso por Incumplimiento no tiene como misión la defensa del principio de tutela judicial efectiva, sustanciándose básicamente, en garantizar que los Estados miembros cumplan con el Derecho de la Unión y evitando que los Estados miembros no cumplan con los objetivos y compromisos por estos alcanzados en los Tratados.

La discrecionalidad que atesora la Comisión para abrir, superada la fase administrativa, la fase jurisdiccional del Recurso por Incumplimiento se ve solapada en esta puesta en común de ambas herramientas con la también discrecionalidad del órgano jurisdiccional del Estado miembro para plantear al TJUE la Cuestión Prejudicial. En el marco del procedimiento de la Cuestión Prejudicial, igualmente, el tribunal dispone de un gran poder discrecional, en tanto puede eludir la contestación open-ended cases, o determinar con mayor o menor rigor la viabilidad de las justificaciones aportadas sobre las medidas comunicadas al órgano jurisdiccional por parte del TJUE, donde este cuenta con una gran libertad en relación con la apreciación de la prueba pues aunque son los Estados miembros quienes deben probar fehacientemente la justificación de la medida, el TJUE se limitara únicamente a verificar si ha quedado suficientemente probado.

El Recurso por Incumplimiento, a diferencia de la Cuestión Prejudicial, se fundamenta en que el primero debe aplicar la carga de la prueba y observar que se respete el principio de contradicción. La Comisión, en este sentido, debe probar concisamente que

\footnotetext{
${ }^{37}$ Véase nota a pie de página 21

${ }^{38}$ GARCÍA ANTÓN, R., "La Cuestión Prejudicial y la fiscalidad directa...” ob. cit., p. 163
} 
se ha producido un incumplimiento, mientras que el mecanismo ejecutado por el organismo jurisdiccional del Estado miembro a través de la Cuestión Prejudicial deberá evidenciar justificadamente la discriminación que se somete aportando las pruebas necesarias donde el TJUE asume un papel onus probandi, eminentemente arbitrario, señalando en ambos supuestos que se ajusta al Derecho de la Unión. El Recurso por Incumplimiento tiene como objeto observar si un Estado ha incumplido sus obligaciones y, en el caso que el Estado no cumpla con la sentencia recaída, el artículo 260.2 del TFUE valora la posibilidad de aperturarse un trámite de ejecución e imponer una multa al Estado miembro incumplidor, mientras que este trámite sancionador no existe en el mecanismo que vehicula la Cuestión Prejudicial ya que en palabras de GARCÍA ANTÓN, el artículo 267 TFUE no se asocia a una condena al Estado miembro por incumplir sus obligaciones con respecto al Tratado, sino estrictamente a la protección de los derechos que el Derecho de la Unión, otorga a sus Ciudadanos.

Señala TIMMERMANS ${ }^{39}$ que tanto el artículo 258 TFUE como el artículo 267 del TFUE se complementan al efecto de conseguir la plena efectividad del Derecho de la Unión Europea. Cada uno desde una perspectiva distinta: el artículo 258 TFUE poniendo al Estado miembro en el centro y el artículo 267 TFUE situando al individuo ${ }^{40}$ en el centro.

\section{V.- CONCLUSIONES}

Con este trabajo se ha podido constatar, a modo comparativo, la situación de dos mecanismos que permiten al TJUE controlar las acciones u omisiones legislativas de los Estados miembros, empresas y Ciudadanos que pudieran ser contrarias al Derecho de la Unión: la Cuestión Prejudicial y el Recurso por Incumplimiento. Las principales conclusiones que se han extraído de este trabajo son las siguientes:

Consideramos necesario un mayor control, convenientemente regulado, de las funciones de la Comisión en aras y aumento de la trasparencia de sus cometidos en cuanto esta institución está facultada normativamente para controlar, mediante el mecanismo del Recurso por Incumplimiento, la aplicación efectiva del Derecho de la Unión por los Estados miembros.

Es indiscutible que la introducción de la herramienta "EU Pilot” ha supuesto un avance significativo en el ámbito de los incumplimientos y que, sin duda, la posibilidad de imposición de una multa coercitiva a los incumplidores, una vez superado un segundo

39 TIMMERMANS, C.W.A., “Judicial Protection against the Member States: Articles 169 and 177 revisited”, en BLOKKER, N.M and MULLER, S. (Eds.), Institutional dynamics of European integration: essays in honour of Henry G. Schermers Vol. II, Martinus Nijhoff Publishers, Dordrecht, 1994, p. 397. Citado en GARCÍA ANTÓN, R., p. 168.

${ }^{40}$ Podríamos llegar considerar al respecto que el Recurso por Incumplimiento es un instrumento que de algún modo se encuentra interrelacionado con la Cuestión Prejudicial, dado que en el caso que puede llegar a ser utilizado por la Comisión en el caso de que la Cuestión Prejudicial no sea puesta en operatividad adecuadamente, la acción de la Comisión, indirectamente permite la tutela de los derechos de los particulares. Citado en LÓPEZ DALLARA, M, L. "Recurso por Incumplimiento y responsabilidad de los Estados miembros...” ob cit. 
procedimiento de infracción, suponen también medidas que en sí mismas han reducido el nivel de incumplimientos por parte de los Ciudadanos, empresas y Estados miembros ${ }^{41}$, pero insistimos en que el control o supervisión son fundamentales.

Un aumento de la trasparencia en las actuaciones de la Comisión, el control de los plazos que en cada momento del procedimiento discurren, así como una delimitación del estatuto jurídico de las partes encartadas en el Recurso por Incumplimiento fortalecería si cabe, los derechos de los Estados miembros con la voluntad de defender con mayor claridad y objetividad a denunciantes, administrados y terceros interesados.

Este control al que concluimos, una vez observados los distintos epígrafes de este trabajo, necesariamente debería considerarse como un control jurídicamente vinculante independiente de que el Recurso por Incumplimiento sea iniciado mediante un procedimiento de oficio por la propia Comisión o a través de una denuncia de un particular.

El nivel de supervisión debería auditar la absoluta discrecionalidad de la que esta goza en todas las fases del Recurso por Incumplimiento y situar, mediante las reformas del procedimiento necesarias, la fijación de los derechos y deberes de los denunciantes considerándoles como parte activa dotados de los derechos que todo procedimiento jurisdiccional otorga a tales. Igualmente, este control jurídico vinculante deberá comprender una clara delimitación de los plazos estableciendo normativamente sus alcances $^{42}$ con el fin de eliminar la inseguridad jurídica a la que las partes se exponen y que desentonan con el carácter que la Unión promulga respecto al principio de seguridad jurídica y que el propio Parlamento Europeo respalda en los continuos informes que este organismo expone al respecto, sobre las funciones de la Comisión "acogiendo con satisfacción el hecho de que, gracias al uso del método del proyecto piloto ("EU Pilot") se hayan acortado los plazos necesarios para la investigación de presuntas infracciones".

\footnotetext{
${ }^{41}$ En este sentido, DE SOUZA SILVA, K., considera que el mecanismo mediante el cual la Comisión pude establecer multas o sanciones pecuniarias, trae importantes ventajas para el esquema político legal comunitario. Primero, por la búsqueda de establecer un equilibrio en la relación entre los efectos del incumplimiento y la pena que el Estado infractor debe soportar por su comportamiento; segundo, porque traslada a la Comunidad la determinación de la sanción, evitando que los Estados miembros practiquen la retorsión, y realicen la justicia por cuenta propia. Además de eso, se observa que la amenaza de una sanción pecuniaria incita a su ejecución cuanto antes. De esta manera, se confirma la vital importancia de los mecanismos presentes en el Derecho supranacional que buscan corregir las infracciones cometidas por algunos de sus entes, visando siempre la lineal progresión de la marcha de la organización europea, en "El Control de la aplicación del Derecho Comunitario en la Unión Europea: Aspectos destacados sobre el procedimiento por incumplimiento.” Revista de Estudios Jurídicos nº 9/2009, p. 20.

${ }^{42}$ Esta alusión a los plazos no es baladí, pues la Comisión dispone de los que seguidamente se enumeraran sin someterse a un control alguno, disponiendo de la discrecionalidad que esta estime, para cada caso particular. Los plazos que sugerimos sean auditados y descritos en una norma de carácter vinculante para las partes serian: plazo para acusar recibo; plazo para comunicar el archivo de la denuncia; plazo para que la Comisión abra el procedimiento mediante una carta de emplazamiento; plazo para que el Estado miembro afectado conteste a dicha carta; plazo para remitir el dictamen motivado; plazo para que el Estado miembro presente observaciones al dictamen; así como que se garantice una adecuada publicidad de las decisiones mediante la publicación obligatoria ya sea en el Diario Oficial de la Unión Europea o en la página web de la Comisión.
} 
Además, el Parlamento considera que se impone una mayor información y aclaración por parte de la Comisión a fin de que los entes de la Unión, entre estos el propio Parlamento, pueda juzgar la funcionalidad de este método para observar desde la herramienta el cumplimiento efectivo por parte de los Estados miembros. Igualmente propone una normativa procesal $^{43}$ en forma de Reglamento sobre la base del fundamento jurídico que se desprende de la nueva descripción del art 298 del TFUE que defina los distintos aspectos del procedimiento de infracción tales como las notificaciones, los plazos vinculantes, el derecho a ser escuchado, la obligación de exponer las razones y el derecho de cada persona a acceder a su expediente, con el fin de reforzar los derechos de los Ciudadanos y garantizar la transparencia sobre el funcionamiento de la Comisión. Todas estas actuaciones y propuestas son sin duda aspectos que deben mejorar la gestión y el funcionamiento de los incumplimientos del Derecho de la UE.

\section{VI.- REFERENCIAS}

ANDRÉS SÁENZ DE SANTAMARÍA, M.P., GONZÁLEZ VEGA, J., y FERNÁNDEZ PÉREZ, B., Introducción al Derecho de la Unión Europea, $1^{\text {a }}$ edición, Eurolex, Madrid, 1996.

BACIGALUPO SAGGESE, M., El sistema jurisdiccional de la Unión Europea, en Principios de Derecho de la Unión Europea, 6a edición, Colex, Madrid.

DE SOUZA SILVA, K., "El Control de la Aplicación del Derecho Comunitario en la Unión Europea: Aspectos Destacados Sobre El Procedimiento Por Incumplimiento”, En Revista de Estudios Jurídicos n ${ }^{\circ}$ 9/2009, p.20.

FARAMIÑÁN GILBERT, J. M. de, "El Control de la Legalidad Comunitaria: El Recurso de nulidad y el Recurso por omisión”, El Derecho Comunitario Europeo y su Aplicación Judicial, (dirigida por Dr. G. C. RODRÍGUEZ IGLESIAS y Dr. D. J. LIÑÁN NOGUERAS), ed. Civitas, Madrid, 1993, p.454.

- "El contencioso de la Unión Europea. El Control de la legalidad en la Unión Europea”, en Tratado de Derecho y Políticas de la Unión Europea, Tomo V, Sistema Jurisdiccional de la UE, Dirigido por José María Beneyto Pérez ed. Thomson Reuters/Aranzadi, Pamplona, 2012, pp. 321-426.

FERNÁNDEZ TOMÁS, A., La Carta de derechos fundamentales de la Unión Europea, Tirant lo Blanch, Valencia, 2001.

\footnotetext{
${ }^{43}$ La doctrina no comparte una necesaria pretensión reguladora o “codificadora”, pues argumenta que hay dudas de si existe base jurídica en los Tratados que permita llevarla a cabo, considera que no existe en los artículos 258 a 260 del TFUE ninguna referencia a la posibilidad de ser objeto de desarrollo a través de un procedimiento legislativo ordinario o especial. Citado en VIÑUALES FERREIRO, S, “Algunas reflexiones sobre la transparencia en el Procedimiento de Infracción en la Unión Europea”. En Cuadernos Manuel Giménez Abad 9 junio 2015, pp 222 y ss.
} 
GARCÍA ANTÓN, R., La Cuestión Prejudicial y la fiscalidad directa. Thesis submitted for assessment with a view to obtaining the degree of Doctor of Laws of the European University Institute Florence, Dir. Dr. Loïc Azoulai, 30 April 2015.

GARCÍA ROCA, J., “Originario y derivado en el contenido de la Carta de los Derechos fundamentales de la Unión Europea: los test de constitucionalidad y convencionalidad”, en HERRERO DE LA FUENTE, A., (Editor), La Carta de los Derechos fundamentales de la Unión Europea. Una perspectiva pluridisciplinar, Cuadernos del Instituto Rei Afonso Henriques de Cooperación Transfronteriza, n1 2, Zamora, 2003, p.63.

IBAÑEZ GARCÍA, I., "El procedimiento pre-contencioso para el control de la aplicación del Derecho comunitario”, en Gaceta jurídica de la Unión Europea y de la competencia, $n^{\circ}$ 248, 2007, p.21.

- "La necesaria regulación del procedimiento de infracción del derecho de la Unión Europea”, Actualidad Administrativa, n 19, 2011. pp.2 y ss.

LÓPEZ DALLARA, M, L. "Recurso por Incumplimiento y responsabilidad de los Estados miembros por actos de sus órganos judiciales en violación de la obligación impuesta por el artículo 234.3 TCE.”, recuperado el 18 de mayo de 2016, en http://noticias.juridicas.com/conocimiento/articulos-doctrinales/4518-recurso-porincumplimiento-y-responsabilidad-de-los-estados-miembros-por-actos-de-sus-organosjudiciales-en-violacion-de-la-obligacion-impuesta-por-el-articulo-234-3-tce/

MARTÍN DELGADO, I., "El procedimiento administrativo en el derecho de la Unión Europea”, en Revista de Derecho de la Unión Europea, n 19, 2010. pp. 99 y ss.

PESCATORE, P., "Van Gend en Loos, 1963. A view from within”, en POIARES MADURO, M. and AZOULAI, L. (Eds.) The Past and the Future of EU Law. The Classics of EU Law revisited on the 50th Anniversary of the Rome Treaty, Hart Publishing, Portland, 2010, p.7.

REBOLLO-PUIG, M., y BUENO-ARMIJO, A., "Los procedimientos administrativos previos al Recurso por Incumplimiento”, en FUERTES, M. (Coord.), Un procedimiento administrativo para Europa, Thomson Reuters- Aranzadi, Navarra, 2012, pp. 343 y 344.

SAIZ ARNAIZ, A., "La Carta de los Derechos Fundamentales de la Unión Europea y los ordenamientos nacionales", Cuadernos de Derecho Público, núm. 13, 2001, p. 156.

SAMPOL PUCURULL, M., "Los procedimientos de infracción. ¿Hay Bases para una Codificación?”, en SORIANO GARCÍA, J, E. (Dir.), Procedimiento Administrativo Europeo, Civitas-Thomson Reuters, Navarra, 2012, pp. 555 a 599.

SMITH, M., "Procedimientos administrativos relacionados con el artículo 258 del TFUE: una perspectiva académica”, en FUERTES, M. (Coord.), Un procedimiento administrativo para Europa, Parlamento Europeo, Bruselas, 2011. 